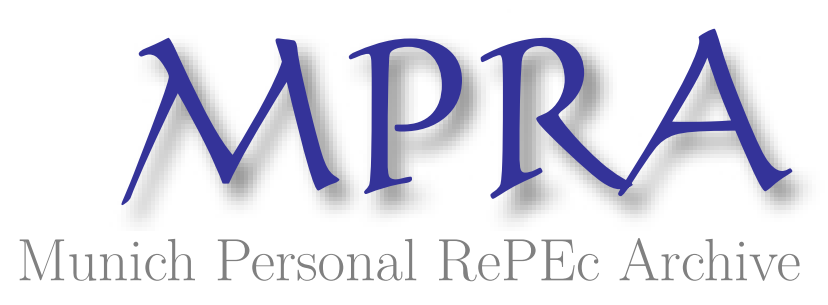

\title{
Frustration, Euphoria, and Violent Crime
}

Rossi, Martin and Munyo, Ignacio

7 November 2021

Online at https://mpra.ub.uni-muenchen.de/110533/

MPRA Paper No. 110533, posted 11 Nov 2021 03:25 UTC 


\title{
Frustration, Euphoria, and Violent Crime*
}

\author{
Ignacio Munyo \\ CERES \& Universidad de San Andrés \\ and \\ Martín A. Rossi \\ Universidad de San Andrés
}

\begin{abstract}
We exploit a series of natural experiments that use real crime data to investigate the effect of a violation of expectancies on violent crime. We study two types of violation of expectancies that generate the emotions of frustration and euphoria. Our empirical designs exploit differential expectations (as measured by the odds of soccer games in the betting market) while maintaining the outcome unchanged (a loss in a soccer game for frustration, a win in a soccer game for euphoria). We find that frustration is followed by a spike in violent crime whereas euphoria is followed by a reduction in violent crime. The two effects are concentrated in a narrow time window after the end of the game: one hour.
\end{abstract}

Keywords: violation of expectancies; soccer; natural experiment; robbery; theft; aggression. JEL Codes: K42.

\footnotetext{
* Ignacio Munyo, imunyo@ceres-uy.org; Martín Rossi, mrossi@udesa.edu.ar. We are grateful to the General Director of the Ministry of the Interior of Uruguay and the Police Department of Montevideo for providing the database on crime, and to Fabián García for providing the database on bets. We are also grateful to Lorena Pompilio for several helpful discussions. The comments of Alex Kacelnik, Christian Ruzzier, Cynthia Schuck-Paim, Devesh Raval, Ernesto Dal Bó, Fred Finan, Juan Dubra, Mauricio Papini, Steven Raphael, Tommy Murphy, and Wladimir Alonso are gratefully acknowledged. Alan Acosta, Rafael Guntin, and Rafael Xavier provided excellent research assistance.
} 


\section{Introduction}

When subjects are exposed to a violation of expectancies they experience an emotional

reaction. If reality is worse than expected the resulting emotion is called frustration and if reality is better than expected the resulting emotion is called euphoria or elation (Amsel 1992; Flaherty 1996). Here, we exploit a series of natural experiments that use real crime data in order to study the link between frustration, euphoria, and violent crime.

The ideal experiment on the effects of frustration and euphoria involves a manipulation of expectations while maintaining the outcome unchanged, an approach that, so far, has been restricted to lab experiments in animals. A typical lab experiment involves two phases. First, subjects in the treated group are trained to respond for a reward of a constant value, creating the expectancy of the same reward in the future. Second, the reward is diminished (frustration) or increased (euphoria) without prior notice, so that expectancies are violated. Finally, the effect of frustration or euphoria is addressed by comparing the behavior of subjects in the treated group to those in a control group that receive the same output but that are not exposed to a violation of expectancies. Under the emotional state of frustration animals show significant changes in physiology (Tranel 1983; Otis and Ley 1993; Scheirer et al. 2002; Papini 2003), neural activity (Abler et al. 2005), and behavior (Crespi 1942; Weinstein 1981; Vacca and Phillips 2005). In particular, frustration causes an increase in aggressive behavior for birds (Dantzer et al. 1980), pigs (Duncan and Wood-Gus 1971), and rats (Tomie et al. 1993), among other vertebrates.

In humans, the potential causal relationship between frustration and aggression (the so called frustration-aggression hypothesis) has been present in the literature of experimental psychology for more than seventy years (Dollard et al. 1939; Berkowitz 1969). However, the empirical support for this hypothesis is meager (Whitley and Kite 2010), probably because it is 
difficult and ethically problematic to induce experimental subjects to behave aggressively (Gottfredson and Hirschi 1993; Baumeister et al. 2010). To overcome the difficulties faced by lab researchers, we exploit a series of natural experiments that use real crime data in order to explore the link between frustration, euphoria, and violent property crime. Our setup exploits a unique database that includes the exact time of all crimes reported in Montevideo, Uruguay, between 2002 and 2010. We focus on property crime: theft (property crime without violence) and robbery (property crime with violence). We combine these data on crime with a database that includes the results of all soccer games played by the main Uruguayan teams between 2002 and 2010, and with a database that includes the odds in the betting market. The combination of information from the betting market and the actual result of the game allow us to categorize periods as being of predominant frustration, euphoria, or no-surprise. We find that frustration is followed by a spike in violent crime, thus providing empirical support to the frustrationaggression hypothesis. We also find that euphoria is followed by a reduction in violent crime. The spike in violent crime after frustration and the dampening in violent crime after euphoria are concentrated in a narrow time window after the end of the game: one hour.

There is a vast literature on the impact of incidental emotions (emotions triggered by a prior experience that is irrelevant to the current situation) such as happiness, fear, and anger on decision making (Vohs et al. 2007). Incidental emotions influence how much people help (Manucia et al. 1984), trust (Dunn and Schweitzer 2005), and are willing to share in an ultimatum or in a dictator game (Andrade and Ariely 2009). Incidental emotions also influence economic decision making such as risk-taking behavior (Kugler et al. 2012) and pricing of different products (Lerner et al. 2004). We contribute to this literature by providing the first 
estimates of the effect of the incidental emotions of frustration and euphoria on decision making, in particular on the decision to engage in violent crime.

Close to our approach is the recent paper by Card and Dahl (2011), who explore the relationship between family violence and the emotional cues associated with wins and losses by professional football teams in the US. Under the assumption that outcomes are as random conditional on expectations, they estimate the causal effect of an upset outcome of the game. Their main finding is that upset losses (losses when expected to win) by the home professional football team lead to an increase in police reports of at-home male-on-female intimate partner violence. The estimation of the impact of an upset outcome involves two different things happening together: the impact of the outcome of the game and the impact of a violation of expectancies. Our contribution to this literature is to isolate the impact of the violation of expectancies from the impact of the outcome of the game. We believe this is important, since a violation of expectancies may arise in very different settings and situations that are not necessarily related to sports.

More generally, our findings provide support to Koszegi and Rabin's (2006) prediction that individuals frame gains and losses around a rationally expected reference point (for a review of the literature on the importance of reference points in observed behavior, see Della Vigna 2009). Our paper is also related to the literature on the link between sports and violence (Sivarajasingam et al. 2005; Gantz et al. 2006; Rees and Schnepel 2009; Priks 2010; Quigg et al. 2012).

The paper continues as follows. Section II describes the data and presents the statistical methods. Section III presents the experimental designs and reports the results. Section IV concludes. 


\section{Data and statistical methods}

\section{Data on crime}

The database on crime was obtained from the Police Department of Montevideo and includes more than 835,000 felonies occurred in Montevideo from January 2002 to December 2010 (Montevideo, the capital of Uruguay, has a population of 1.5 million of inhabitants). It comprises the universe of criminal incidents recorded, with information on the date and the exact hour of the incident.

A critical feature of the database is that includes real-time information. The time of the offense is recorded as soon as the crime is reported. Under the usual procedure, the police officer takes detailed information from the victim that includes the time of the incident. Given the precision required for our research, this is a key advantage relative to other sources of crime information such as victimization surveys. Although victimization surveys avoid the usual underreporting problem of police-recorded offenses, the exact time of the occurrence is generally missed since the victim is asked to recall the details of an event that occurs several months ago.

We focus on property crime, which encompass the two most frequent types of crime: theft and robbery. Theft is defined as depriving a person of property without the use of violence (60 percent of all police-recorded offenses in Montevideo in the period 2002 to 2010), whereas robbery is defined as depriving a person of property with the use of violence or threat of violence (10 percent of the offenses in our database). Violence is defined as an intentional use of physical force or power.

Summary statistics are reported in Table 1.

Data on soccer results and odds in the betting market 
Aside from crime data, our database includes information on the date, the exact hour, and the results of every official game played either by Nacional or Peñarol (the two Uruguayan biggest soccer teams) between 2002 and 2010. Our focus on soccer games is motivated by the fact that in Uruguay most of the population feels strong emotional attachment to one of these two teams. ${ }^{1}$ According to a recent poll, in Montevideo 80 percent of the population supports either Peñarol or Nacional (approximately 40 percent for each team), around ten percent support one of the 14 small teams, and the remaining ten percent have no preference for any soccer team. ${ }^{2}$

Finally, the database incorporates the information on the complete record of odds in the betting market for all the games played by Nacional and Peñarol since 2005. We use the odds in the betting market as a proxy for fans' expectations. The bets provide relatively accurate predictions of the final result of the matches: the correlation between being the favorite team according to the bets and winning the game is 0.40 (significantly different from zero at the 1 percent level).

\section{$\underline{\text { Statistical methods }}$}

To explore the effect of frustration and euphoria on property crime we track the number of thefts and robberies in Montevideo in the 7-hour window centered on the end of games played by Nacional and Peñarol against small teams. For a given soccer match, we define hour zero as the hour in which the end of the game effectively occurs (thus hour zero is not always the same chronological hour). Hour one is then defined as the hour immediately following the end of the game, hour minus one is the hour preceding the end of the game, and so on. This event-study

\footnotetext{
1 "All the Uruguayans are born shouting a goal and that is why there is so much noise in the maternity wards, there is a tremendous din. I wish to be a soccer player as all Uruguayan children do" (Galeano 1995).

${ }^{2}$ MPC Consulting: "Peñarol y Nacional son dos de las tres instituciones en el mundo con mayor número de hinchas en relación a la población de su país."
} 
methodology is well known in empirical finance (Fama et al. 1969; Browman 1983; MacKinlay 1997).

We define crime to be unusually high (low) when the number of crimes recorded in a given date is significantly higher (lower) than the number of crimes recorded the same day at the same hour in the previous week. That is, we say that crime is unusually high when the number of crimes on Sunday 16 November 2008 at 5pm is significantly higher in statistical terms than the number of crimes on Sunday 9 November 2008 at $5 \mathrm{pm} .^{3}$ By computing week variations, we control for the daily and weekly cycles observed in crime (one week is a relatively short period of time in order to have variations in crime trend levels). In addition, we compute the change in crime with respect to a control group (as defined below). That is, to detect abnormal crime we compute a double difference: difference with respect to the previous week plus difference with respect to a control group.

\section{Experimental designs and results}

The first experiment identifies the causal effect of frustration on crime by comparing the number of crimes after an unexpected loss (the treated group) to the number of crimes after an expected loss (the control group). By exploiting differential expectations while maintaining the outcome unchanged, this design allows us to distinguish frustration from other related emotions arising from just losing a game.

The second experiment identifies the causal effect of euphoria on crime by comparing the number of crimes after an unexpected win to the number of crimes after an expected win. Again, this design allows us to distinguish euphoria from other related emotions arising from winning a game.

\footnotetext{
${ }^{3}$ Assuming that the weekly variations in police-recorded offenses are independently and identically distributed, we cannot reject the null hypothesis that week variations in police-recorded offenses follow a normal distribution.
} 
The experimental designs are described in Table 2. The identification assumption is that expectations are as random conditional on outcomes. Identification would be challenged in the presence of omitted variables that are correlated with both expectancies and crime. For example, if more fans attend a game in which their team is favored to win and the number of fans attending a game is correlated with crime, this would create a bias in our estimates.

To address the potential concern of omitted variable bias our strategy is as follows: under the assumption that omitted variables should affect violent and non-violent crime in a similar way, the presence of an effect of a violation of expectations on violent crime in combination with the absence of an effect of a violation of expectancies on non-violent crime can be interpreted as providing support to our identification assumption.

We provide evidence to support the assumption that omitted variables affect in a similar way the two types of property crime. First, thefts and robberies have a similar daily and weekly pattern (Figure 1). During the day, thefts and robberies present low levels of criminal activity early in the morning, a steady increase since 5-7am leading to a peak at $8 \mathrm{pm}$. Throughout the week, thefts and robberies look relatively flat from Monday to Thursday, present a peak on Friday, and a decrease during the weekend. Second, thefts and robberies react in a similar way to the set of observable covariates. As shown in Table 3, thefts and robberies have a positive trend during the sample period. In addition, thefts and robberies rise with temperature and hours of sunshine, and decrease with temperature squared, rainfall, and during holidays. ${ }^{4}$

Overall, our assumption that thefts and robberies react in a similar way to unobservable characteristics is supported by the fact that robberies and thefts (i) have a similar daily pattern, (ii) have a similar weekly pattern, (iii) have a positive trend during the sample period, and (iv) react in a similar way to observable characteristics.

\footnotetext{
${ }^{4}$ Similar conclusions are obtained when we use a Poisson model for count data instead of OLS.
} 


\section{$\underline{\text { Frustration }}$}

We identify the impact of frustration on crime by comparing the number of crimes after an unexpected loss (the treated group, $\mathrm{E}(\mathrm{W}) / \mathrm{L}$ ) to the number of crimes after an expected loss (the control group, $\mathrm{E}(\mathrm{L}) / \mathrm{L})$. Thus, we want to estimate $[\mathrm{E}(\mathrm{W})-\mathrm{E}(\mathrm{L})] / \mathrm{L}$, where $\mathrm{L}$ denotes a loss, $\mathrm{W}$ a win, and $\mathrm{E}($.$) the pre-game expectation.$

This experiment is based on the games that Nacional and Peñarol lost against other teams. In our sample period there are 67 games where the odds anticipated the big teams to be winners but they finally lost (the treated group), and 19 cases where the big teams were expected to be defeated and they lost the game (the control group). In total, there are 86 games, seven hours, and 602 observations.

As depicted in column (1) in Table 4, violent crime (as measured by robberies) shows a significant jump after a frustrating loss. The increase in violent crime after frustration is quantitatively important: robberies increase 70 percent with respect to the control group. ${ }^{5}$

The effect of frustration on violent crime is short-termed, being statistically significant only for the first hour from the game end. This finding is in line with the emotion literature, which has traditionally worked under the assumption that the intensity of an emotional state fades away rather quickly, along with its impact on behavior (Isen et al. 1976; Ekman 1999). ${ }^{6}$

As reported in column (2) in Table 4, there is no statistically significant variation in thefts after a frustrating lost. Indeed, the number of thefts is decreasing one hour after the end game, suggesting a possible substitution between violent property crime and non-violent property crime.

\footnotetext{
${ }^{5}$ The magnitude of the reversal of expectations seems to matter, but not too much. If we split the sample of unexpected losses we find that the coefficient one hour after the end of the games is 1.025 ( $p$-value $=0.015)$ for the 47 games where the odds are smaller than 2:1 and 1.034 (p-value=0.033) for the 20 games where the odds are higher than $2: 1$.

${ }^{6}$ The results remain unchanged when we include the set of controls used in Table 3.
} 
The finding that violent crime is increasing and non-violent crime is decreasing (or at least not increasing) provides empirical support to our identification assumption. ${ }^{7}$ Our empirical strategy, for example, controls for possible confounding factors such as temperature and rainfall that affect both thefts and robberies. The only identification concern should arise from those confounding factors that are correlated with violent crime but not with crime per se. For example, identification would be jeopardized if games where the big team is expected to win attract a more violent attendance to the stadium, and this more violent attendance is in turn associated with more robberies but not with more thefts. To address this concern we exclude from the sample those crimes committed in the jurisdiction of the stadium where the game was played (Montevideo has 24 jurisdictions), and we find similar results. This indicates that the increase in violent crime is not explained exclusively by unruly behavior of fans attending the game. Instead, the spike in violence spreads over the entire city. We also collected data on the amount of money spent in gambling for the games included in our sample (a proxy for how much expectation generates the game). We find that the amount of money spent in gambling is not correlated with the pre-game bets. This indicates that even if this variable belongs to the model of violent crime, its omission is not biasing our estimates. ${ }^{8}$

\section{Euphoria}

The second experiment identifies the effect of euphoria on crime by comparing the number of crimes after an unexpected win to the number of crimes after an expected win ([E(L)$\mathrm{E}(\mathrm{W})] / \mathrm{W})$. In our sample period there are 18 games where the odds anticipated the big teams to lose but they finally won (the treated group, $\mathrm{E}(\mathrm{L}) / \mathrm{W}$ ), and 205 cases in where the big teams were

\footnotetext{
${ }^{7}$ The non-significant finding on thefts also suggest that the results are not driven by an over reporting of crime due to emotional cues.

${ }^{8}$ In line with our findings and interpretation, Card and Dahl (2011) report a low correlation between the fraction of households watching a game and the pre-game spread, and interpret the result as evidence that their results are not driven by changes in viewership.
} 
expected to win and ended up winning the game (the control group, EW)/W). ${ }^{9}$ In total, there are 223 games, seven hours, and 1,561 observations.

As observed in column (3) in Table 4, euphoria has the effect of reducing violent crime, a reduction that, again, is only statistically significant for one hour after the game end. The reduction in robberies is 42 percent relative to the control group. Again, there is no impact of euphoria on thefts (column (4) in Table 4). ${ }^{10}$

Finally, our empirical strategy that tracks both violent and non-violent property crime avoids alternative explanations for the observed results such as incapacitation. ${ }^{11}$ If celebrations after euphoric victories reduce criminal activity and the lack of celebrations after frustrating defeats increase criminal activity these effects should affect both violent and non-violent crimes. Neither frustration nor euphoria significantly affects the number of thefts.

\section{Conclusions and discussion}

Our results show that emotional cues have a socially meaningful effect on behavior. In particular, emotions associated to an unexpected soccer result produce a significant variation in fans' aggressive behavior, increasing violent crime after frustration and reducing violent crime after euphoria. The fact that a violation of expectancies has a significant effect on violent property crime but no effect on non-violent property crime leads us to believe that the link between the violation of expectancies and the increase in violent property crime is causal.

\footnotetext{
${ }^{9}$ In order to increase statistical power we include in the sample international games (that is, games played by Nacional and Peñarol against teams from other countries) played between 2002 and 2005. For these games there is no information available on bets. However, given that in the period 2005-2010 (when odds are available) for international games the home team was the favorite to win in more than 96 percent of the games, we assume that for those international games played between 2002 and 2005 the favorite is always the home team.

${ }^{10}$ When we include the set of controls, the sign of the coefficient one hour after the game end do not change, but it becomes less significant (a p-value of 0.25 ).

${ }^{11}$ The incapacitation effect is well accepted by economists and criminologists to be an important predictor of criminal activity.
} 
Our findings, in combination with the previous findings in animals, indicate that the link between frustration and aggression is a general phenomenon in nature, and suggest an underlying physiological mechanism shaped by natural selection. There is an important body of research showing that under the emotional state of frustration the body releases catecholamine hormones, including adrenaline and noradrenaline. These hormones provide the body a burst of energy and facilitate immediate physical reactions associated with a preparation for violent muscular action (the fight-or-flight response, first described by Canon 1915), reducing in this way the entry cost into violence. Indeed, it is well documented that the release of catecholamine is positively correlated with aggressive behavior (Ekkers 1975; Hamburg et al. 1975; Bell and Hepper 1987).

The literature on rational choice theory in criminology postulates that rational agents decide whether to engage in criminal activities by comparing the benefits and costs of committing a crime, i.e. agents compare the financial reward from crime to the return from legal work, taking into account the probability of apprehension and the severity of the punishment (Becker 1968). Our results indicate that the decision to engage in violent property crime is also influenced by the emotional state of the individual, and suggest that a fraction of crime against the property can be better characterized as a breakdown of control rather than a behavior driven by rational choice. 


\section{References}

Abler, B., Walter, H. Erk, S., 2005. Neural correlates of frustration. NeuroReport 16 (7), $669-672$.

Amsel, A., 1992. Frustration Theory: An Analysis of Dispositional Learning and Memory. New York: Cambridge University Press.

Andrade, E., Ariely, D., 2009. The enduring impact of transient emotions on decision making. Organizational Behavior and Human Decision Processes 109, 1-8.

Baumeister, R., DeWall, C., Vohs, K., Alquist, K., 2010. Does emotion cause behavior (apart from making people do stupid, destructive things)? In: Agnew, C., Carlston, C., Graziano, D., Kelly, J. (Eds). Then a Miracle Occurs: Focusing on Behavior in Social Psychological Theory. New York: Oxford University Press.

Becker, G., 1968. Crime and punishment: an economic approach. Journal of Political Economy 76, 169-217.

Bell, R., Hepper, P., 1987. Catecholamines and aggression in animals. Behavioural Brain Research 23 (1), 1-21.

Berkowitz, L., 1962. Aggression: A Social Psychological Analysis. New York: McGrawHill.

Browman, R., 1983. Understanding and conducting event studies. Journal of Business and Accounting 10, 561-584.

Canon, W., 1915. Bodily Changes in Pain, Hunger, Fear and Rage: An Account of Recent Researches into the Function of Emotional Excitement. Appleton-Century-Crofts.

Card, D., Dahl, G., 2011. Family violence and football: the effect of unexpected emotional cues on violent behavior. Quarterly Journal of Economics 126 (1), 103-143. 
Crespi, L., 1942. Quantitative variation in incentive and performance in the white rat. American Journal of Psychology 40, 467-517.

Dantzer, R., Arnone, M., Mormede, P., 1980. Effects of frustration on behaviour and plasma corticosteroid levels in pigs. Physiology \& Behavior 24 (1), 1-4.

Della Vigna, S., 2009. Psychology and economics: evidence from the field. Journal of Economic Literature 47, 315-372.

Dollard, J., Doob, L., Miller, N., Mowrer, O., Sears, R., 1939. Frustration and Aggression. New Haven: Yale University Freer.

Duncan, I., Wood-Gus, D., 1971. Frustration and aggression in the domestic fowl. Animal Behaviour 19 (3), 500-504.

Dunn, J., Schweitzer, M., 2005. Feeling and believing: The influence of emotion on trust. Journal of Personality and Social Psychology 6, 736-748.

Ekkers, C., 1975. Catecholamine excretion, conscience function and aggressive behavior. Biological Psychology 3 (1), 15-30.

Ekman, P., 1999. Basic emotions. In: Dalgleish, T., Power, M. (Eds.). Handbook of Cognition and Emotion. Sussex: John Wiley \& Sons.

Fama, E., Fisher, L., Jensen, M., Roll, R., 1969. The adjustment of stock prices to new information. International Economic Review 10 (1), 1-21.

Flaherty, C., 1996. Incentive Relativity. New York: Cambridge University Press.

Galeano, E., 1995. El Fútbol a Sol y Sombra. Siglo XXI de España Editores.

Gantz, W., Bradley, S., Wang, Z., 2006. Televised NFL games, the family, and domestic violence. In: A. Raney, A., Bryant, J. (Eds.). Handbook of Sports and Media. Mahwah: Erlbaum. 
Gottfredson, M., Hirschi, T., 1993. A control theory interpretation of psychological research on aggression. In: Felson, R., Tedeschi, J. (Eds.). Aggression and Violence: Social Interactionist Perspectives. Washington DC: American Psychological Association.

Hamburg, D., Hamburg, B., Barchas, J., 1975. Anger and depression in perspective of behavioral biology. In: Levi, L. (Ed.). Emotions: Their Parameters and Measurement. New York: Raven Press.

Isen, A., Clark, M., Schwartz, M., 1976. Duration of the effect of good mood on helping: Footprints on the sands of time. Journal of Personality and Social Psychology 34, 385-393.

Koszegi, B., Rabin, M., 2006. A model of reference-dependent preferences. Quarterly Journal of Economics 121 (4), 1133-1165.

Kugler, T., Connolly, T., Ordóñez, L., 2012. Emotion, decision and risk: betting on gambles vs. betting on people. Journal of Behavioral Decision Making 25, 123-134.

Lerner, J., Small, D., Loewenstein, G., 2004. Heart strings and purse strings: Carry-over effects of emotions on economic transactions. Psychological Science 15 (5), 337-341.

MacKinlay, C., 1997. Event studies in economics and finance. Journal of Economic Literature 35 (1), 13-39.

Manucia, G., Baumann, D., Cialdini, R., 1984. Mood influences on helping: Direct effects or side effects? Journal of Personality and Social Psychology 46, 357-364.

Otis, J., Ley, R., 1993. The effects of frustration induced by discontinuation of reinforcement on force of response and magnitude of the skin conductance response. Bulletin of the Psychonomic Society 31 (2), 97-100. 
Papini, M., 2003. Comparative psychology of surprising nonreward. Brain, Behavior and Evolution 62, 83-95.

Priks, M., 2010. Does frustration lead to violence? Evidence from the Swedish hooligan scene. Kyklos 63 (3), 450-460.

Quigg, Z., Hughes, K., Bellis, M., 2012. Effects of the 2010 World Cup football tournament on emergency department assault attendances in England. European Journal of Public Health, August (Epub ahead of print).

Rees, D., Schnepel, K., 2009. College football games and crime. Journal of Sports Economics 10, 68-86.

Scheirer, J., Fernandez, R., Klein, J., Picard, R., 2002. Frustrating the user on purpose: a step toward building an affective computer. Interacting with Computers 14, 93-118.

Sivarajasingam, V., Moore, S., Shepherd, J., 2005. Winning, losing, and violence. Injury Prevention 11 (2), 69-70.

Tomie, A., Carelli, R., Wagner, G., 1993. Negative correlation between tone (CS-) and water induces target-biting in rats. Animal Learning and Behavior 21, 355-359.

Tranel, D., 1983. The effects of monetary incentive and frustrative nonreward on heart rate and electrodermal activity. Psychophysiology 20, 652-657.

Vacca, G., Phillips, A., 2005. Inhibition of successive positive contrast in rats withdrawn from an escalating dose schedule of D-amphetamine. International Journal of Comparative Psychology 18, 298-306.

Vohs, K., Baumeister, R., Loewenstein, G., 2007. Do Emotions Help or Hurt Decision Making? A Hedgefoxian Perspective. New York: Russell. 
Weinstein, L., 1981. Incentive contrast effects in humans with monetary reinforcement and reaction time. Acta Psychologica 47, 83-87.

Whitley, B., Kite, M., 2010. The Psychology of Prejudice and Discrimination. Belmont: Wadsworth Cengage Learning. 
Figure 1. Daily and weekly cycle of robberies and thefts (average 2002-2010)
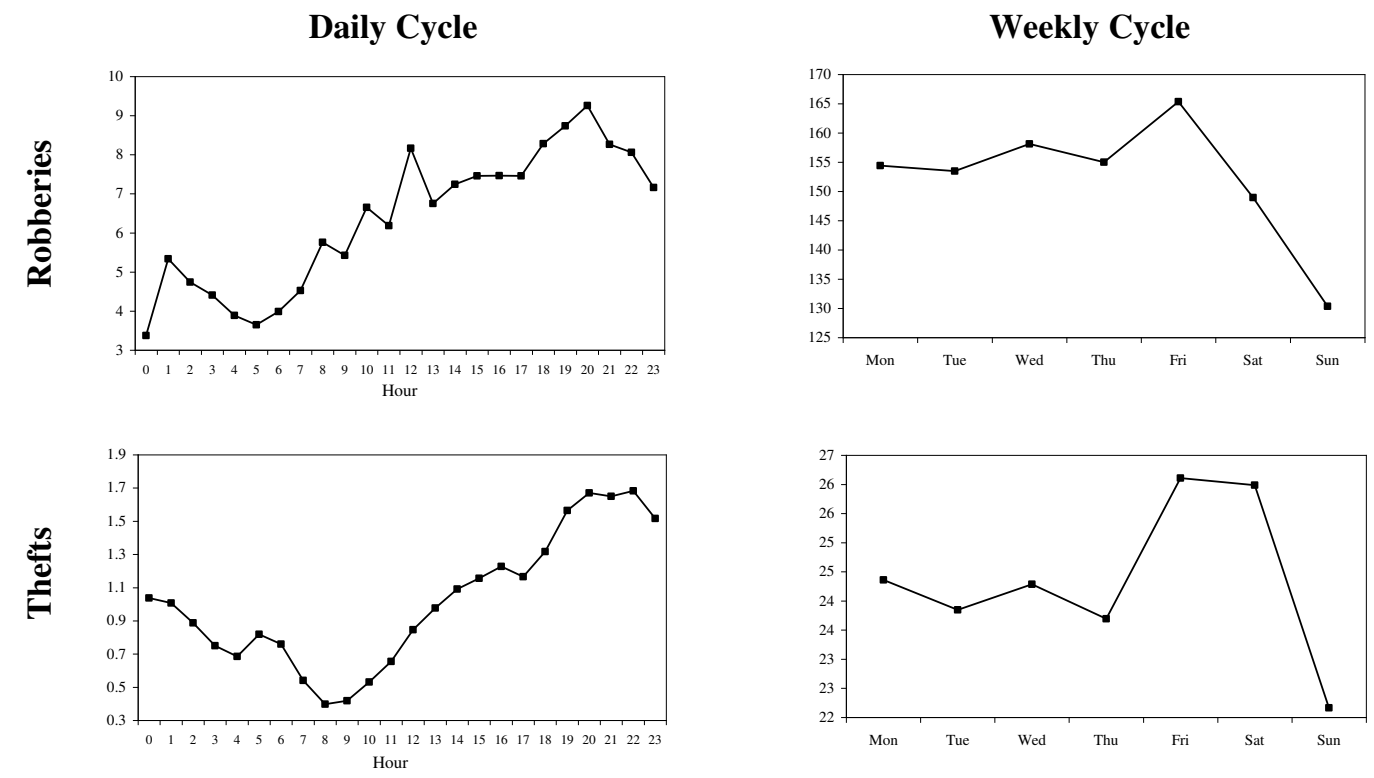

Notes: Robbery is defined as depriving a person of property with the use of violence or threat of violence (10 percent of all police-recorded offenses in Montevideo in the period 2002 to 2010). Theft is defined as depriving a person of property without the use of violence (60 percent of all police-recorded offenses in Montevideo in the period 2002 to 2010). 
Table 1. Summary statistics

\begin{tabular}{cccccccc}
\hline \hline & Frequency & Unit & Mean & $\begin{array}{c}\text { Standard } \\
\text { Deviation }\end{array}$ & Minimum & Maximum & Observations \\
\cline { 2 - 8 } Robberies & hourly & offenses & 1.0 & 1.2 & 0 & 10 & 78,312 \\
Thefts & hourly & offenses & 6.3 & 3.5 & 0 & 33 & 78,312 \\
Temperature (average) & daily & Celsius & 16.3 & 5.3 & 3.0 & 30.9 & 3,270 \\
Rainfall & daily & $\mathrm{mm}$ & 3.2 & 10.1 & 0 & 138 & 3,287 \\
Holidays & daily & & 0.04 & 0.20 & 0 & 1 & 3,287 \\
Sunshine & daily & hours & 7.2 & 4.1 & 0 & 14.1 & 3,287 \\
\hline
\end{tabular}


Table 2. Experimental designs

\begin{tabular}{cccccc}
\hline \hline Experiment & $\begin{array}{c}\text { Parameter } \\
\text { Estimated }\end{array}$ & Group & Outcome & Expectation & $\begin{array}{c}\text { Number of } \\
\text { Games }\end{array}$ \\
\hline \multirow{2}{*}{ I } & Frustration: & Treatment & Lose & Win & 67 \\
& {$[\mathrm{E}(\mathrm{W})-\mathrm{E}(\mathrm{L})] / \mathrm{L}$} & Control & Lose & Lose & 19 \\
\hline \multirow{2}{*}{ II } & Euphoria: & Treatment & Win & Lose & 18 \\
& {$[\mathrm{E}(\mathrm{L})-\mathrm{E}(\mathrm{W})] / \mathrm{W}$} & Control & Win & Win & 205 \\
\hline
\end{tabular}


Table 3. Determinants of robberies and thefts

\begin{tabular}{|c|c|c|c|c|}
\hline & \multicolumn{2}{|c|}{ Robberies } & \multicolumn{2}{|c|}{ Thefts } \\
\hline & (1) & (2) & (3) & (4) \\
\hline \multirow[t]{2}{*}{ Temperature } & $0.341 * *$ & $0.299 * *$ & $4.382 * * *$ & $3.002 * * *$ \\
\hline & $(0.139)$ & $(0.130)$ & $(0.624)$ & $(0.472)$ \\
\hline \multirow{2}{*}{${\text { (Temperature })^{2}}^{2}$} & $-0.009 * *$ & $-0.009 * *$ & $-0.127 * * * *$ & $-0.088 * * *$ \\
\hline & $(0.004)$ & $(0.004)$ & $(0.020)$ & $(0.016)$ \\
\hline \multirow[t]{2}{*}{ Rainfall } & $-0.033 * * *$ & $-0.039 * * *$ & $-0.091 *$ & -0.022 \\
\hline & $(0.012)$ & $(0.011)$ & $(0.052)$ & $(0.033)$ \\
\hline \multirow[t]{2}{*}{ Holidays } & $-5.602 * * *$ & $-5.147 * * *$ & $-30.015 * * *$ & $-32.037 * * *$ \\
\hline & $(0.696)$ & $(0.685)$ & (3.687) & (3.266) \\
\hline \multirow[t]{2}{*}{ Daylight } & 0.028 & 0.031 & $0.744 * * *$ & $0.551 * * *$ \\
\hline & $(0.031)$ & $(0.029)$ & $(0.144)$ & $(0.105)$ \\
\hline \multirow{2}{*}{ Linear trend } & $0.004 * * *$ & & $0.011 * * *$ & \\
\hline & $(0.000)$ & & $(0.001)$ & \\
\hline Day of the week dummies & Yes & Yes & Yes & Yes \\
\hline Month dummies & Yes & Yes & Yes & Yes \\
\hline Year dummies & No & Yes & No & Yes \\
\hline Observations & 3,270 & 3,270 & 3,270 & 3,270 \\
\hline
\end{tabular}

Notes: All models are estimated by OLS. Newey-West robust standard errors are in parentheses. ***Significant at 1 percent level; **Significant at 5 percent level; *Significant at 10 percent level. 
Table 4. Main results

\begin{tabular}{ccccc}
\hline \hline & \multicolumn{2}{c}{ Frustration } & \multicolumn{2}{c}{ Euphoria } \\
& {$[\mathbf{E}(\mathbf{W})-\mathbf{E}(\mathbf{L})] / \mathbf{L}$} & \multicolumn{2}{c}{$\mathbf{[ \mathbf { L }}(\mathbf{W})] / \mathbf{W}$} \\
\cline { 2 - 5 } Hour & $\begin{array}{c}\text { Robberies } \\
(1)\end{array}$ & Thefts & Robberies & Thefts \\
$(2)$ & $(3)$ & $(4)$ \\
\hline-3 & -0.241 & 0.258 & 0.278 & -0.068 \\
& $(0.480)$ & $(1.039)$ & $(0.424)$ & $(0.883)$ \\
-2 & 0.510 & -2.083 & 0.410 & -1.085 \\
& $(0.446)$ & $(1.269)$ & $(0.389)$ & $(0.653)$ \\
-1 & -0.677 & 0.807 & 0.190 & -1.004 \\
& $(0.418)$ & $(0.750)$ & $(0.456)$ & $(0.857)$ \\
0 & 0.234 & -0.136 & 0.042 & -1.209 \\
& $(0.460)$ & $(1.185)$ & $(0.393)$ & $(0.817)$ \\
1 & $1.027 * * *$ & -1.609 & $-1.024 * *$ & 0.269 \\
& $(0.383)$ & $(1.190)$ & $(0.456)$ & $(1.027)$ \\
2 & 0.203 & -0.084 & -0.337 & -0.218 \\
& $(0.363)$ & $(0.960)$ & $(0.434)$ & $(0.955)$ \\
3 & -0.199 & 0.261 & -0.434 & -0.626 \\
& $(0.453)$ & $(0.923)$ & $(0.271)$ & $(0.765)$ \\
\hline
\end{tabular}

Notes: Standard errors are in parentheses. ${ }^{* * * \text { Significant at } 1}$ percent level; **Significant at 5 percent level. 